PPPL-2841

PPPL-2841

UC-426

\title{
EXPERIMENTS ON TFTR SUPERSHOT PLASMAS
}

BY

J.D. STRACHAN, M. BELL, A. JANOS, ET AL.

May, 1992

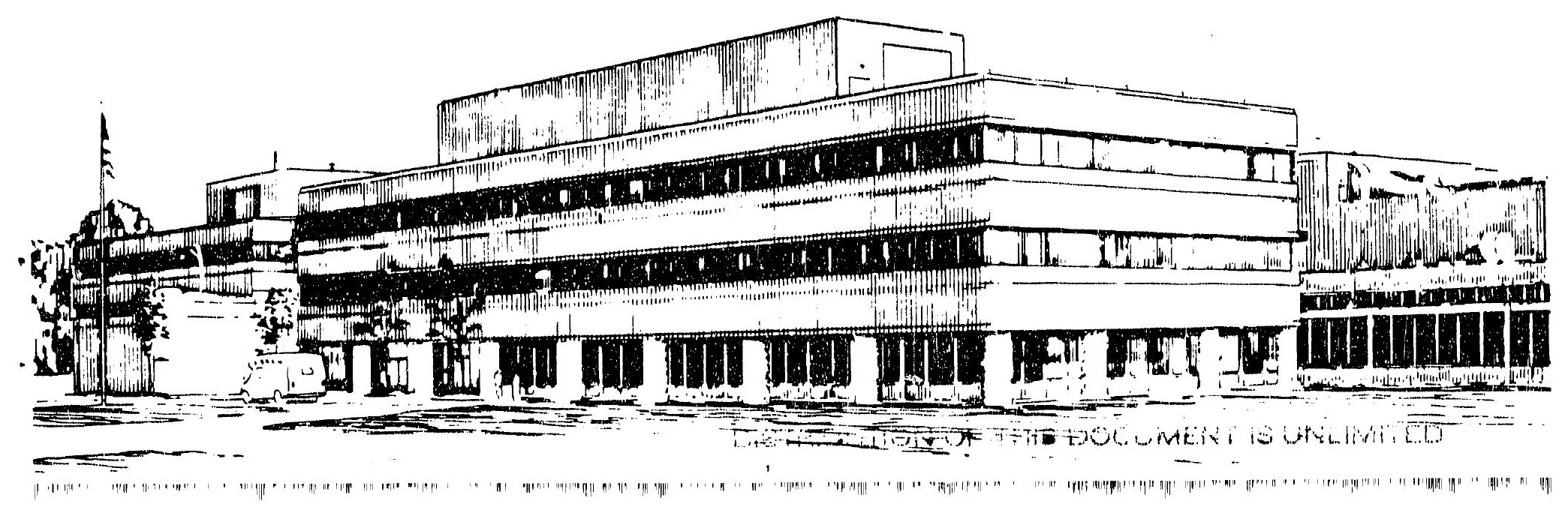




\section{NOTICE}

This report was prepared as an account of work sponsored by an agency of the United States Government. Neither the United States Government nor any agency thereof, nor any of their employees, makes any warranty, express or implied, or assumes any legal liability or responsibility for the accuracy, completeness, or usefulness of any information, apparatus, product, or process disclosed, or represents that its use would not infringe privately owned rights. Reference herein to any specific commercial produce, process, or service by trade name, trademark, manufacturer, or otherwise, does not necessarily constitute or imply its endorsement, recommendation, or favoring by the United States Government or any agency thereof. The views and opinions of authors expressed herein do not necessarily state or reflect those of the United States Government or any agency thereof.

\section{NOTICE}

This report has been reproduced directly from the best available copy.

Available to DOE and DOE contractors from the:

Office of Scientific and Technical Information P.O. Box 62

Oak Ridge, TN 37831 ;

Prices available from (615) 576-8401.

Available to the public from the:

Natiorial Technical Information Service

U.S. Department of Commerce

5285 Port Royal Road

Springfield, Virginia 22161

$703-487-4550$ 


\title{
Experiments on TFTR Supershot Plasmas
}

\author{
J.D. Strachan, M. Bell, A. Janos, S. Kaye, S. Kilpatrick, D. Manos, \\ D. Mansfield, D. Mueller, K. Owens, C:S. Pitcher,${ }^{1}$ J. Snipes,${ }^{2}$ and J. Timberlake \\ Princeton Plasma Physics Laboratory, Princeton University \\ PPPL--2841 \\ Princeton, NJ 08543 USA \\ DE92 013638
}

Improvements to the TFTR limiter have extended the threshold for carbon blooms (an uncontrolled massive influx of (arbon) to greater than $32 \mathrm{MW}$ for $1 \mathrm{sec}$ so that blooms seldom occur in present TITR Supershot experiments. As a result of the progression from strong blooms to modest blooms to no blooms, improvements in confinement could be correlated with the occurrance of a carbon bloom in the plasma which immediately preceded the supershot. It is speculated that the carbon influx during a carbon bloom results in a limiter surface which has a slightly reduced self-sputtering yield for the subsequent discharge. The influence on the supershot plasma seems similar to phenomena obtained by conditioning with lithium pellets.

${ }^{1}$ Canadian Fusion Fitels Technology Project, Toronto, Canada

2 .IIT, Plasma Fusion Center, Cambridge, MA

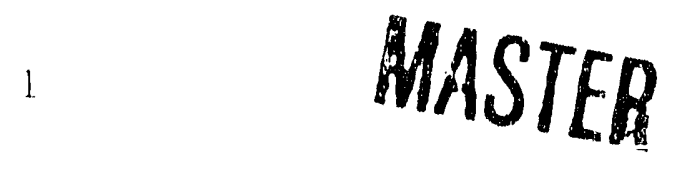




\section{Introduction}

The TFTR experiment is expected to begin tritium operation in the middle of 1993. Some of the goals of these experiments [1] are (1) demonstration of significant fusion power production by simultaneously bringing together the requirements of plasma confinement, stability, power handling capability, and machine operation; (2) characterization of phenomena associated with energetic fusion alpha particles in the plasma [2] including alpha particle confinement, alpha slowing down duration, alpha orbit and ripple loss rates, and alpha collective instabilities; and (3) identification of phenomena specific to tritium plasma operation including tritium particle confinement and fueling, scaling of plasma performance with ion mass, operation of tritium pellets, and tritium RF heating modes.

The first two of these goals place a premium upon operation of TFTR at high power and with long confinement times in regimes that produce the maximum fusion ncutron emission. For TFTR, this means that plasma operation in the supershot regime [3] with neutral beam powers greater than $30 \mathrm{MW}$ is desired. Some of the important issues are (1) maximizing the plasma confinement so that the fusion rate is maximized (Fig. 1), (2) establishing reproducible plasma conditions in order that differences in plasma behavior can be confidently attributed to the presence of tritium or alpha particles in the plasma, and (3) maintaining optimal conditions for durations that are comparable at least to the alpha slowing-down duration. Resolution of the third issue would allow the alpha density to build to a maximum value and would rnake alpha instabilities as visible as possible.

It turns ont that a major factor in each of these issues is the plasma interaction with the limiter. Much TFTR experimental research effort has been directed at modifying the Dhisma-wall interaction with the hope of improving performance with respect to one of the 
above issues.

This paper will report results from the CY90 TFTR campaign to alter the plasma-wall interaction and to raise $Q_{D D}[4]$. This campaign was extensive and consisted of about 2800 plasma shots, of which about 1500 were devoted to discharge cleaning pulses. As is implied by this ratio, the most important consideration in these efforts was the plasma-wall interaction. The experiments included modifications to the limiter to eliminate carbon blooms, a disruptive discharge cleaning campaign, and the deposition of thin films upon the limiter. An important part of this paper will be to describe the impact of a carbon bloom $[5,6]$ upon the plasma. Carbon blooms develop when the local surface temperature on small areas of the graphite tiles exceed $1700^{\circ} \mathrm{C}$ and radiation enhanced sublimation [ $\left.i\right]$ of the carbon occurs. A carbon bloom is often coincident with a decrease in plasma confinement time. However, the existence of a bloom in the preceding plasma often correlated with an improved plasma confinement in a manner consistent with an improved or mose conditioned limiter.

\section{Elimination of Carbon Blooms}

TFTR has a circular plasma cross-section with a toroidal inner wall bumper limiter made of carbon. The plasmas reported here were run with $\mathrm{R} / \mathrm{a}=2.45 \mathrm{~m} / 0.80 \mathrm{~m}$, plasma currents of $1 \rightarrow 2 \mathrm{MA}$, neutral beam heating powers of $10 \mathrm{MW} \rightarrow 32 \mathrm{MW}$, and toroidal magnetic fields of $3.9 \rightarrow 5.2 \mathrm{~T}$. The measurements [8] of une $\mathrm{H}_{\alpha}$ light $\left(\mathrm{H}_{\alpha}+\mathrm{D}_{\alpha}\right.$ Balmer line), and CII (657.8 mm) light used to characterize the plasma limiter interaction were made at one toroidal location and averaged over five chords (Fig. 2). These emission levels are intorpreted as proportional to the hydrogenic and carbon influxes. This approximation tis silpportad by 
the observation that the electron density for the ohmic stages of all (approximately 2000) $R$ $=2.45 \mathrm{~m}$ plasmas was consistent with a plasma composed only of hydrogenic species and carbon ions each having an influx described by the $\mathrm{H}_{\alpha}$ and CII light emission measured by the detectors in Fig. 2. The ratio of deuterium to carbon ion content was in the range of $\sim$ $1 / 3$ to 3 for the CY90 ohmic plasmas.

Prior to the CY90 run, several changes were made to the TFTR inner wall bumper limiter [9] in order to eliminate carbon blooms. Firstly, one-third of the original POCO graphite tiles were replaced with Carbon Fiber Composite tiles in order to reduce spalling and cracking that led to hot spots where blooms preferentially originated. The tiles that were replaced were those located near the horizontal midplane since they often received the highest power loading. Secondly, the edges of diagnostic holes in the limiter were bevelled to reduce the power fluxes, and thus eliminate blooms that previously arose at these edges. Lastly, of the tiles at the midplane were realigned to within $\approx \pm 0.5 \mathrm{~mm}$ of a surface referenced to the vacuum vessel. The intention was to reduce the peak heat flux by spreading the heat load more uniformly over the limiter surface. It was felt that misalignment may have led to hot spots that were the source of blooms. Following these changes, blooms that had previously occurred after about $0.5 \mathrm{sec}$ for all plasmas with beam powers $>22 \mathrm{MW}$ did not occur even for discharges with 32 MW of beam heating for 1 sec.

Comparison of similar $30 \mathrm{MW}, 1.6 \mathrm{MA}, 5.0 \mathrm{~T}$ supershot plasmas from CY'S8 (37083 which had a bloom after about 0.5 sec of beam heating) and CY90 ( 51553 which was bloom free for the (ull 1 sec of beam heating) indicates the typical result that in CYgo there was slightly more stored energy (5\%) and neutron emission (10\%) since the confinement time (Fig. 3) was $10 \%$ higher for the lisst 0.35 sec of beam heating. This improvement in (YYOO over

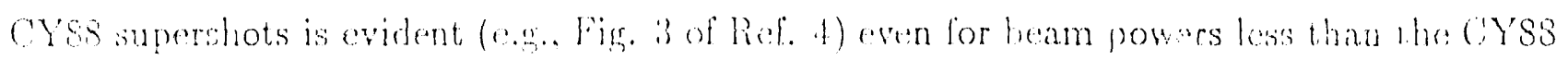


bloom threshold of $22 \mathrm{MW}$. The maximum density peakedness was about the same for these two plasmas $\left.\left(\mathrm{n}_{e}(0) /<\mathrm{n}_{e}\right\rangle=2.25\right)$ occurring at about $0.35 \mathrm{sec}$ into the beam heating. For supershot plasmas, density peakedness often correlates with energy confinement [10]. The power to the limiter (calculated as $\mathrm{P}_{\text {Beam }}-\mathrm{dE} / \mathrm{dt}-\mathrm{P}_{R A D}$ ) (Fig. 3) was higher by $\approx 10 \%$ for the bloom plasma due to the strong $\mathrm{dE} / \mathrm{dt}$ term when the confinement time degraded from 0.45 to $0.7 \mathrm{sec}$ (Fig. 3). Observations of many edge signals showed that a bloom started at 0.45 sec in the CY88 plasmas (e.g., Fig. 3). Thus, the comparison of the CY88 and CY90 plasmas can be made for times less than $0.5 \mathrm{sec}$ when neither plasma was influenced by a bloom and after $0.5 \mathrm{sec}$ when only the CY88 plasma was influenced by a bloom. Coincident with the bloom, $\tau_{E}$, was reduced to about $70 \%$ of the value in the bloom-free.plasma (Fig. 3) and was near L-mode values.

Evidently (Fig. 3), the elimination of the bloom did not actually improve the peak supershot performance since the plasma without the bloom also degraded after about 0.4 sec of beam heating. The improvement in plasma performance prior to 0.4 sec cannot be associated with the elimir stion of the carbon influx from the bloom since the CY88 plasma was not being influe.nced by a large carbon influx at this time. The origin of the improvement before $0.4 \mathrm{sec}$ is possibly related to $\sim 10 \%$ enhancement of the beam power at a given voltage [11] in CY90 compared to CY88. However, it is also possible that the better alignment and different composition of the limiter may have altered the plasma performance in a manner that had changed $\tau_{E}$. 


\section{Benefit of a Preceding Bloom}

During the initial period of operation in 1990 , carbon blooms did occur at high neutral beam powers. However, as the run progressed their frequency decreased, and the power threshold increased (Fig. 4). Moreover, the total influx of carbon during blooms was reduced by about an order to magnitude after about 5,000 plasmas (Fig. 5). Thus, the source of the blooms in CY90 was not a broken tile or a tile edge that was continually exposed to high plasma heat flux, but several sources that were cured by repeated exposure. Ohservations of the limiter after the run indicated that some tile edges had been eroded.

In the initial 1,000 plasma attempts when the sporadic blooms still yielded a large carbon influx, it was observed that the supershot plasmas with the highest $\tau_{E}$ had been preceded by a discharge having a carbon bloom (Fig. 6). The plasmas with the highest $\tau_{E}$ and fusion rate also had the lowest CII light emission in the target plasma just prior to the application of the beam heating. Evidently, the bloom reduced the carbon influx in the ohmic phase of the subsequent plasma and improved the energy confinement time of the beam heated phase.

The benefit of the bloom was restricted to the next plasma since only individual plasmas have been improved in Fig. 6. An intervening ohmic plasma significantly reduced the berieficial effect of the bloom. Evidently, the benefit induced by the bloom did not involve gradual cleanup or improvement of the limiter. It can be speculated that the improvement resulted from a thin carbon film deposited on the limiter surface by the bloom. If it were an effect attributed to the thin flim, then the film must have been worn away, covered up, or have been saturated by the intervening plasma. For example, after boronization [12], the resulting $100 \mathrm{~nm}$ Boron coating is worn away or covered up by about 30 TTTF plasmiss so 
it might be expected that the carbon film was a few nm thick.

\section{Other Methods for Inducing Blooms}

By the time we were convinced that blooms correlated with an improvement to subsequent supershot performance, the limiter was so well conditioned that significant blooms no longer occurred (see Fig. 5). Therefore, techniques were developed to induce blooms. These techniques included:

(a) Operating a shot at smaller major radius (e.g., $R=2.3 \mathrm{~m}$ ) to induce a bloom. The next shot, would then be at $R=2.45 \mathrm{~m}$ with the attendant benefit from the bloom induced in the previous discharge. The plasmas at smaller major radius caused more power density to be applied to the midplane portion of the limiter. Limiter thermocouple measurements [13] indicated that about 50\% more energy was deposited on the central portion of the limiter. The hotter tiles had bulk temperatures $\left(\sim 70^{\circ}\right)$ about twice as hot as for $\mathrm{R}=2.45 \mathrm{~m}$ operation. The poloidal distribution of CII light and $\mathrm{H}_{\alpha}$ light on the limiter during the bloom were narrower than for the blooms at $R=2.45$ m. Since this method required investing an entire plasma shot to induce the bloom, it was time consuming and was discontinued.

(b) Moving the plasma to smaller major radius towards the end of the beam heating phase. This increases the power loading on the limiter and tends to induce blooms. This method produces large blooms; however, occasionally the target CII light on the subsequent plasma was higher rather than lower. Evidently, there is an uncuantified upper limit for the magnitude of the bloom that will induce a beneficial effect. 'The effect of "too-large" a bloom on the subsequent plasma was similar to that of a pre- 
ceding disruption and, at its worst, even requires discharge cleaning and recovery time. Due to the recovery time and irreproducible nature of these blooms, this technique was discontinued.

(c) Applying a shaping magnetic field to make the plasma more oblate (by about $4 \%$ ). The blooms induced by application of the shaping field are also probably a result of increasing the power density on the limiter midplane. These blooms were among the largest produced in CY90; however, after a few such blooms, application of the field no longer induced a bloom. During such blooms, a large amount of $\mathrm{H}_{\alpha}$ light has been observed delayed by $\approx 0.2 \mathrm{sec}$ from the CII light. The poloidal distribution of CII emission was narrower for the first $0.2 \mathrm{sec}$, and then became broader and similar to the $\mathrm{H}_{\alpha}$ pattern. Some attempts at inducing such blooms featured only a short duration of the shaping field pulse in order that a controlled amount of hydrogen could be released in the bloom.

(d) Setting the plasma current and toroidal magnetic field so that the Shafranov safety factor at the plasma edge was equal to 4 . In this condition, intense MHD activity ( $m=4$ ) was observed on the Mirnov coils. Coincident with the MHD activity, the CII emission increases and the following discharge also improves. The CII spatial distribution during these blooms is broader than for the natural blooms as is the $\mathrm{H}_{\alpha}$ emission. The power to the limiter tends to increase as the MHD increases since $\tau_{E}$ falls (similar to $\mathrm{P}_{L I M}$ in Fig. 3). Event11ally, these blooms also were considerably reduced since the same magnitude of MHD signal would no longer significantly enhanced the carbon influx. Presumably, the MHD rearranges the location of the power deposition on the limiter, lengthens the scrape-off length, and sweeps the power across the limiter. 
These effects tend to reduce the power loading to limiter locations that usually take most of the power while increasing the power to other regions of the limiter. Thus, small carbon particles or unconditioned limiter surfaces could be releasing carbon and hydrogen during this type of induced bloom.

While all of the techniques to induce blooms benefitted the subsequent supershot plasma, each tended to become progressively more difficult to induce and control. The limiter released less carbon after repeated application of the different heat loads that each technique . presented. Thus, techniques also were attempted that involved depositing films from external sources on the limiter. A carbon rod was inserted to within a $\mathrm{cm}$ of the plasma from below and the plasma was moved down onto it in order to ablate carbon from the probe. Difficulties with induced disruptions, probe damage, and adequate diagnostics of the down shifted plasma terminated use of the carbon probe to induce blooms. During CY90, the most successful of these conditioning ideas was the injection of lithium pellets into the plasma [14]. The lithium pellets seem to influence the supershot plasma in a manner similar to preceding blooms except that the lithium pellets are more reproducible. This might be expected since the pellets have a better defined magnitude, duration, and localization than do blooms. It has been speculated that the lithium pellets deposit a film on the limiter which reduces the carbon sputtering coefficient [14].

All of the above four techniques to induce blooms led to increases of the carbon influx in the bloom-like event. The edge density rise caused by the bloom was observed to be proportional to the CII signal enhancement associated with the bloom indicating that an actual particle influx occurred during the bloom. The magnitude of $\mathrm{H}_{\alpha}$ light in the bloom tended to be larger for blooms with larger CII light with some variation. The ratio of $H_{0}$ 
and CII light in the ohmic target plasma was proportional (Fig.7) to the ratio of $\mathrm{H}_{\alpha}$ to CII light during the beam heating of the preceding plasma. Evidently, the deuterium influx from the limiter is related to the amount of deuterium in the previous plasma and a bloom does not act specifically on the deuterium recycling.

The CII light in the ohmic target plasma was found empirically to depend upon the plasma current $\left(I_{p}\right)$ and time-integrated CII light (IC2) from the previous discharge by

$$
C I I \propto I_{p}^{1.38} I C 2^{-0.1}
$$

where the dependence upon each variable can be seen explicitly (Fig.8), and the weak de. pendence on IC2 is compensated by its wide range. The largest preceding IC2 values in Fig, 8 are associated with the appearance of a carbon bloom, and the lowest values are associated with the preceding plasma being entirely ohmic. It is not clear that a bloom is actually required to obtain the low CII target values since IC2 is approximately the sum of a bloom induced contribution and a contribution which occurs without the bloom. The portion occurring without the bloom is observed to be proportional to the beam power. It is possible that a benefit might arise from high power, long duration beam heating plasma sequences, but this has not be explored on TFTR.

\section{Relation to Confinement Time}

Statistical analysis of all the CY90 $R=2.45 \mathrm{~m}$ supershot plasmas indicates that the confinement time (at time of peak neutron emission) [15] can be expressed in terms of the CII light emission in the ohmic target plasma just prior to the neutral beam turn on. There was no correlation with the $\mathrm{H}_{\alpha}$ light emission in the ohmic target plasma. The full regression 
formula for the confinement time was

$$
\tau_{E} \propto(B)^{1.07}\left(I_{p}\right)^{0.22}\left(W_{B}\right)^{-0.56} C_{N B}^{0.30} C I I^{-0.32}
$$

where $B$ is the toroidal magnetic field, $I_{p}$ is the plasma current, $W_{B}$ is the beam voltage, $\mathrm{C}_{N B}=\frac{P_{c a}}{P_{B}}$ where $\mathrm{P}_{c o}$ is the tangential beam power in the direction of the plasma current, and $P_{B}$ is the total beam power. The dependence upon the carbon influx in the ohmic target plasma can be seen directly when the other parameters are held constant (Fig. 9). The nature of or the existence of a preceding bloom wid not influence the dependence of confinement upon carbon influx in Fig. 9. The lithium pellet improved plasmas have about 10 msec higher confinement times at the same ohmic target carbon influx (Fig. 9).

The time evolution of $\tau_{E}$ through each discharge (e.g., Fig. 3) cannot he determined from Eq. (2) since all the variables are generally constant in time. Regression analysis [16] of many CY90 plasmas indicated that the time evolution of supershot confinement could be described by

$$
\tau_{E} \propto H_{\alpha}^{-0.24}
$$

There are other variables that can be significant, such as $n_{e}(0)$, the central electron density, and, $\beta_{\|} / \beta_{\perp}$, the magnetically deduced pressure anisotropy. The choice of variables is degenerate with other variables, since the edge electron density could replace $\mathrm{H}_{\alpha}$; and $\mathrm{H}(0)$. the peakedness of the neutral beam deposition, could replace $\beta_{\|} / \beta_{1}$ and $n_{e}(0)$. However, a good fit to a wide variety of discharge evolutions is obtained with Eq. (3). The time evolution of the CII light is not a good correlator with the time evolution of $\tau_{E}$ since the CII lignt is commonly constant in time while $\tau_{E}$ degrades in time (e.g., Fig. 3). Equation (3) indicates that a correlation of continement with edge recycling can describe the $\tau_{E}$ degradiation of supershot plasmas with blooms, or supershots wirh MHD. or supershots free of both MIID 
and blooms (Fig. 10).

Equations (2) and (3) appear to contain contrary scalings since Eq. (2) indicates that the ohmic target carbon influx, but not hydrogen influx, is important for supershot confinement at the time of peak neutron emission whereas Eq. (3) indicates that the time evolution of $\tau_{E}$ in supershots depends upon the time evolution of the hydrogen influx but not the carbon influx. These facts possibly could be reconciled if the limiter interaction were somehow different during the ohmic and beam beating phases. The situation is further complicated by energy balance calculations of the change in the plasma transport coefficients [16] that occcurs when $\tau_{E}$ has changed. The principal change is that the central ( $\mathrm{r} / \mathrm{a}<0.4$ ) particle diffusivity is reduced while the peripheral $(r / a>0.6)$ transport coefficients are unchanged when $\tau_{E}$ is increased.

\section{Discharge Cleaning}

The correlation of supershot confinement with reduced carbon influx changes the role of TFTR discharge cleaning sequences. Helium discharge cleaning [17] has been routinely used to recover supershots after TFTR operation with different plasma types and, as well, helium discharge cleaning sequences are often interspersed into supershot campaigns. However, the helium discharge cleaning (Fig. 11) acts primarily upon the hydrogen level in the limiter wall; and the carbon influx changes only slightly. It was even possible for a slight increase in CII light to occur for helium discharge cleaning sequences that followed high power supershots. This increase might be due to a buildup of leelium in the limiter resulting in more carbon release from helium sputtering. Helium discharge cleaning can reduce the carbon influx following L-mode run sequences and distuptions (Fig. 11) after which the limiter produces 
a bigher carbon influx. Helium discharge cleaning is most useful for conditioning when the limiter is emitting high levels of carbon, but may not be as useful when supershot conditions have been attained.

The evolution of the supershot confinement time during the entirc CY90 run (about 7000 plasmas) (Fig. 12) indicates that events such as boronization [18] and a disruptive discharge cleaning [19] campaign did not change $\tau_{E}$ for plasmas not preceded by a bloom. The disruptive discharge cleaning (DDC) campaign was sufficiently effective that a $1 \mathrm{MA}$ ohmic disruption that had tripled the CII light emission on the next helium discharge cleaning plasma at the beginning of the DDC campaign, did not increase the CII light at all by the end of the DDC campaign. Figure 12 also indicates the absence of a long term conditioning effect on the limiters, even though there was over $50 \mathrm{GJ}$ of energy deposited on the limiter by plasma bombardment during the course of the CY90 run.

\section{Summary}

This paper has described the CY90 experiments to alter the supershot confinement by altering the plasma wall interaction. The principal results are that supershot plasmas are improved by reduction in the carbon influx in the ohmic target plasma (before beam heating) and reductions in the hydrogen influx during the beam heating.

\section{Acknowledgment}

This work was supported by the U.S. Department of Energy Contract No. DE-AC02-76CIIO-3073. 
The authors thank A. Ramsey for interesting discussions and measurement of the hydrogen and carbon light. 


\section{References}

[1] D. Meade, et al., Proc. of Thirteenth International Conference on Plasma Physics, and Controlled Nuclear Fusion Research (Washington, 1990) paper IAEA-CN-53/A-1-1.

[2] S.J. Zweben, et al., Nucl. Fusion 28 (1988) 2230.

[3] J. D. Strachan, et al., Phys. Rev. Lett. 58 (1987) 1004.

[4] D. Jassby, et al., Phys. Fluids B 3 (1991) 2308.

[5] A.T. Ramsey, et al., Princeton Plasma Physics Laborator" Report. No. PPPL-2701 (1990).

[6] M. Ulrickson, et al., J. Nucl. Mat. $176 / 177$ (1990) 44.

[7] J. Roth, E. Victike, A.A. Haasz, Nucl. Fusion, Suppl. Vol. 1 (1991) 63.

[8] A.T. Ramsey and S.L. Turner, Rev. Sci. Instrum 58 (1987) 1211.

[9] G.W. Barnes, D. Loesser, D.K. Owens, and M. Ulrickson, Proc. IEEE Conference (1991), to be published.

[10] H. Park, Plasma Phys. Contr. Fus. 31 (1989) 2035.

[11] J. Kamperschroer, et al, Princeton Plasma Physics Report No. PPPL-2763 (1991).

[12] H.F. Dylla, et al., J. Nucl. Mat. 176/177 (1990).

[1.3] A. Janos, tet al., this conference.

[14] J. Snipes, et al., European Conf, on Plasma Physics and Contr. Fusion (Berlin, 1991); J. Snipes, et al, this conference. 
[15] J.D. Strachan, "Neutron Emission from TFTR Supershots," to be published.

[16] J.D. Strachan, et al., "Studies of Energy Confinement in TFTR Supershots," to be published.

(17] H.F. Dylla, et al., Nucl. Fusion 27 (1987) 1221.

(18) H.F. Dylla, et al., J. Nucl. Mat. 176/177 (1990).

[19] H.F. Dylla, J. Nucl. Mat. 145/147 (1987) 48. 


\section{Figures}

Fig. 1. Neutron emission from the $d(d, n)^{3}$ He fusion reaction in TFTR supershots plotted against the beam power. The $(x)$ points have confinement time, $\tau_{E}=0.11 \rightarrow 0.12$ sec, and the $(\square)$ points have $\tau_{E}=0.14 \rightarrow 0.15 \mathrm{sec}$. The same plasma conditions that optimize $d(d, n)^{3}$ He fusion rates are expected to optimize the $d(t, n) \propto$ fusion rate [15] when tritium is introduced into TFTR supershots.

Fig. 2. Schematic diagram of the $\mathrm{H}_{\alpha}$ and CII diagnostic. The $\mathrm{H}_{\alpha}$ and $\mathrm{CII}$ measurements are summed over all five cbords.

Fig. 3. Evolution of the energy confinement $\tau_{E}$, CII light, and power to the bumper limiter, $\mathrm{P}_{L I M}$, for a bloom-free CY90 plasma (dashed line) and a CY88 plasma with a bloom. For both plasmas: $\mathrm{P}_{B}=30 \mathrm{MW}, \mathrm{I}_{p}=1.6 \mathrm{MA}, \mathrm{B}=5 \mathrm{~T}$, and $\mathrm{R}=2.45 \mathrm{~m}$.

Fig. 4. Evolution of the applied beam power to supershot plasmas during the 1990 campaign. The $(x)$ points did not have blooms, the ( $\square$ ) points did have blooms.

Fig. 5. Evolution of the magnitude of CII light associated with the blooms during the 1990 campaign.

Fig. 6. Evolution of the supershot confinement time for the first 1,000 plasmas of the 1990 campaign. The $(\mathrm{x})$ points were supershot plasmas not preceded by a bloom, and the (ㅁ) points were preceded by a bloom.

Fig. T. Ratio of hydrogenic t; carbon influxes in the ohmic target plasma ploited against the time-integrated hydrogenic to carbon influx in the preceding plasma. The preceding 
plasma did not have a bloom for the $(x)$ points, had a naturally occurring bloom for the (ㅁ) points, and had an induced bloom for the $(+)$ points.

Fig. 8. The carbon influx ( $\propto$ CII light emission) in the ohmic target plasma plotied against the integrated carbon influx on the preceding plasma for three ranges of plasma current $(x)$ points have $I_{p}=1.55 \rightarrow 1.65 \mathrm{MA},(\square)$ points have $I_{p}=1.35 \rightarrow 1.45 \mathrm{MA}$, and $(\bullet)$ points have $I_{p}=1.8 \rightarrow 1.9 \mathrm{MA}$.

Fig. 9. The supershot energy confinement time, $\tau_{E}$, at the time of peak neutron emission (usually $0.4 \rightarrow 0.6 \mathrm{sec}$ after the start of the beam heating) plotted against the CII light intensity in the ohmic target plasma just prior to the start of the beam heating. The (x) points were not preceded by a bloom, the ( $\square$ ) points were preceded by a naturally occurring bloom, the ( $\square)$ points were preceded by an induced bloom, and the $\left(^{*}\right)$ points were aided by Lithium pellets. Each set of data is separated into five intervals, 'and the error bars are the statistical deviation of the mean. The points without error bars indicate that only one data point existed in the interval. There were 457 plasmas in the plot. For all the plasmas $\mathrm{B}=4.8 \rightarrow 5.2 \mathrm{~T}$ and $\mathrm{I}_{p}=1.4 \rightarrow 1.7 \mathrm{MA}$.

Fig. 10. The energy confinement time, $\tau_{E}$, of supershot plasmas during the beam heating plotted against the hydrogen influx, $\mathrm{H}_{\alpha}$. Each data point represents a different time in (x) one of four supershot plasmas experiencing a bloom, or ( $\square$ ) one of three supershot plasmas experiencing large MHD (3/2 mode) or ( ) one of two supershot plasmas which where bloom-free and MHD-free [15].

Fig. 1. Hydrogen $(x)$ and carbon $(\square)$ influx in helium discharge cleaning pulses following a 1 MA ohmic disruption near the end of a disruptive discharge cleaning campaign. 
Fig. 12. The supershot energy confinement time, $\tau_{E}$, of supershot plasmas plotted against stiot number. None of the plasmas were aided by lithium pellets nor preceding blooms. $\mathrm{B}=4.8 \rightarrow 5.2 \mathrm{~T}$ and $\mathrm{I}_{p}=1.4 \rightarrow 1.7 \mathrm{MA}$ for all plasmas. 


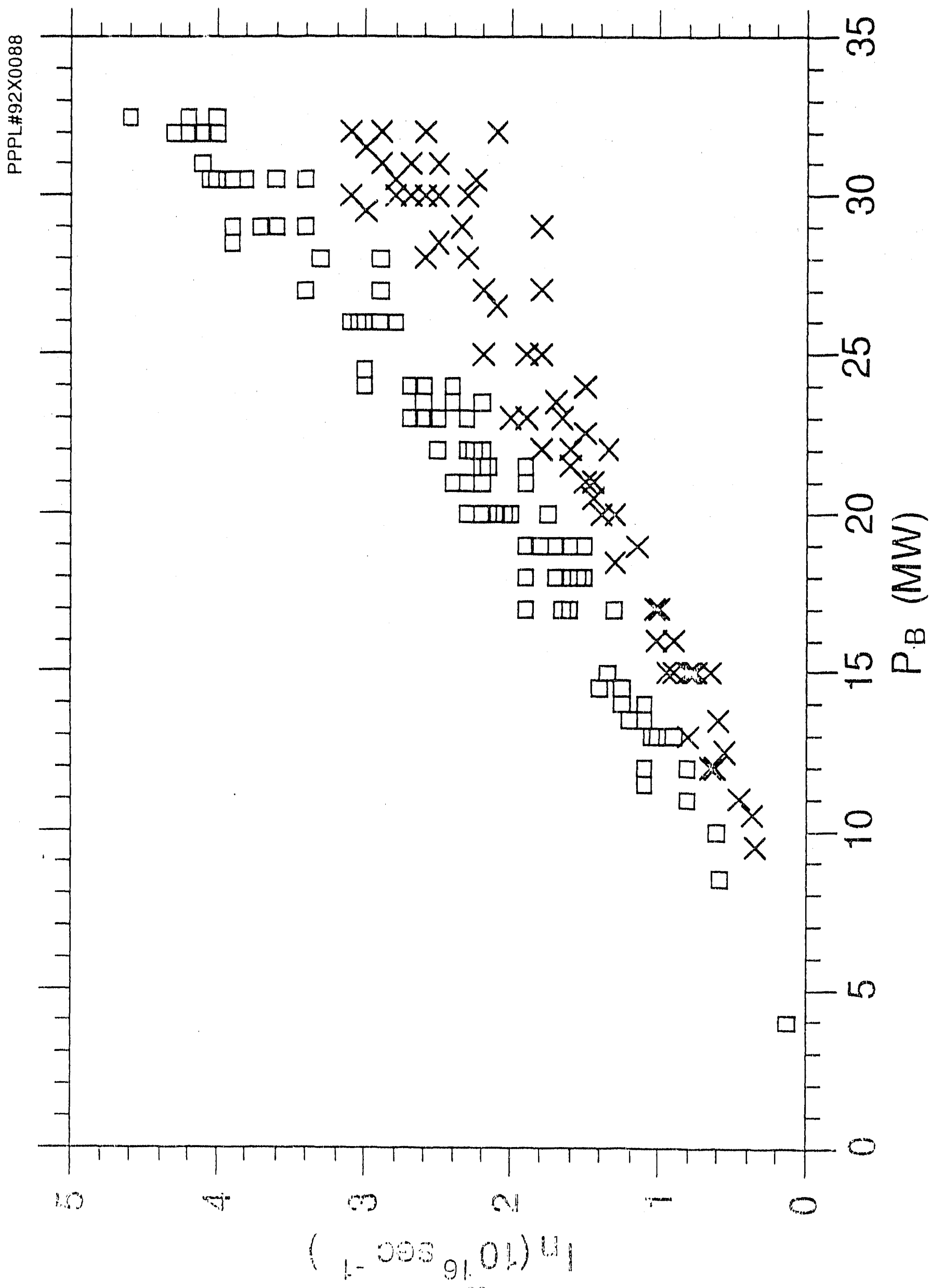


0
0
0
0
$\times$
0
0
$\vdots$
0
0
0
0

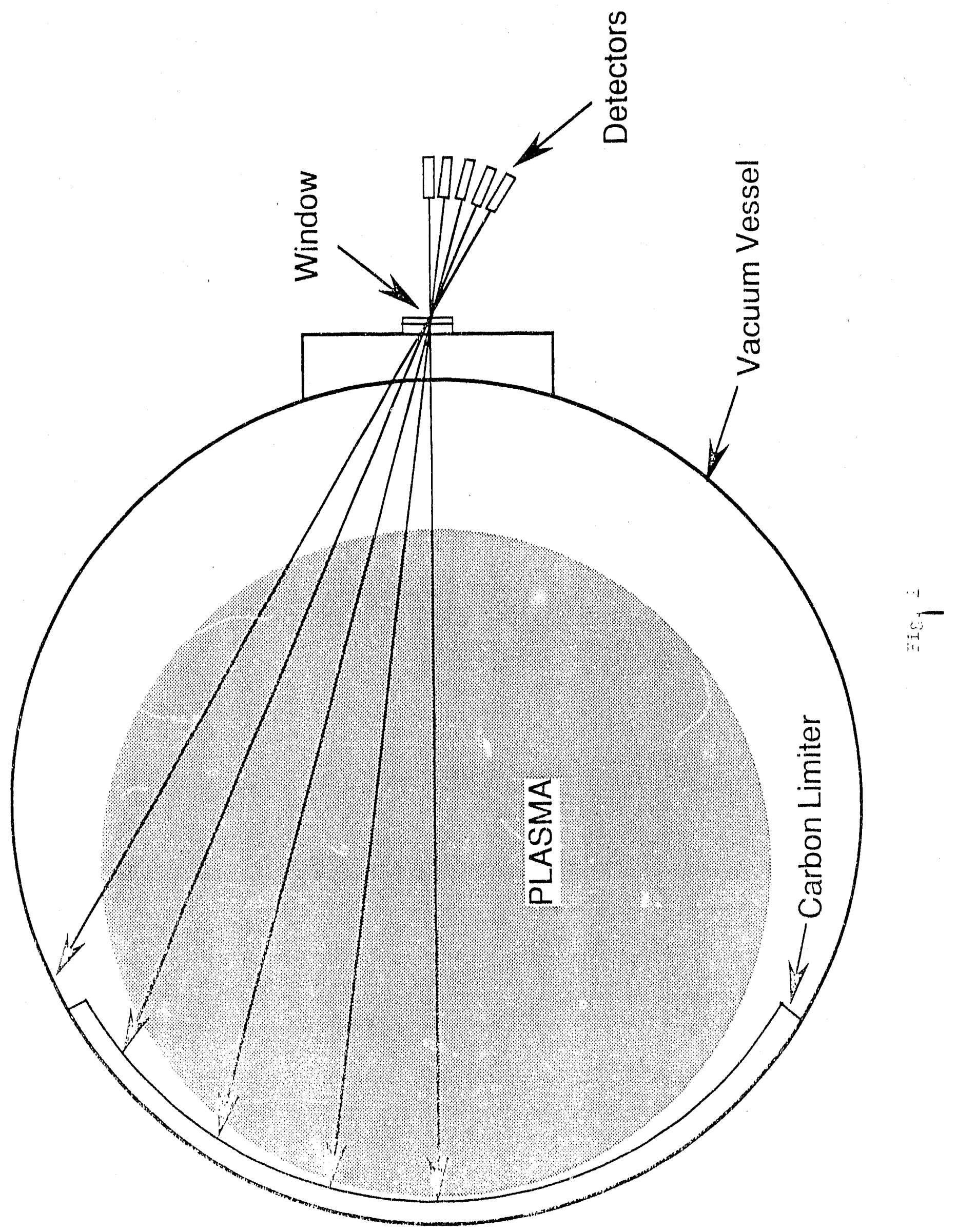




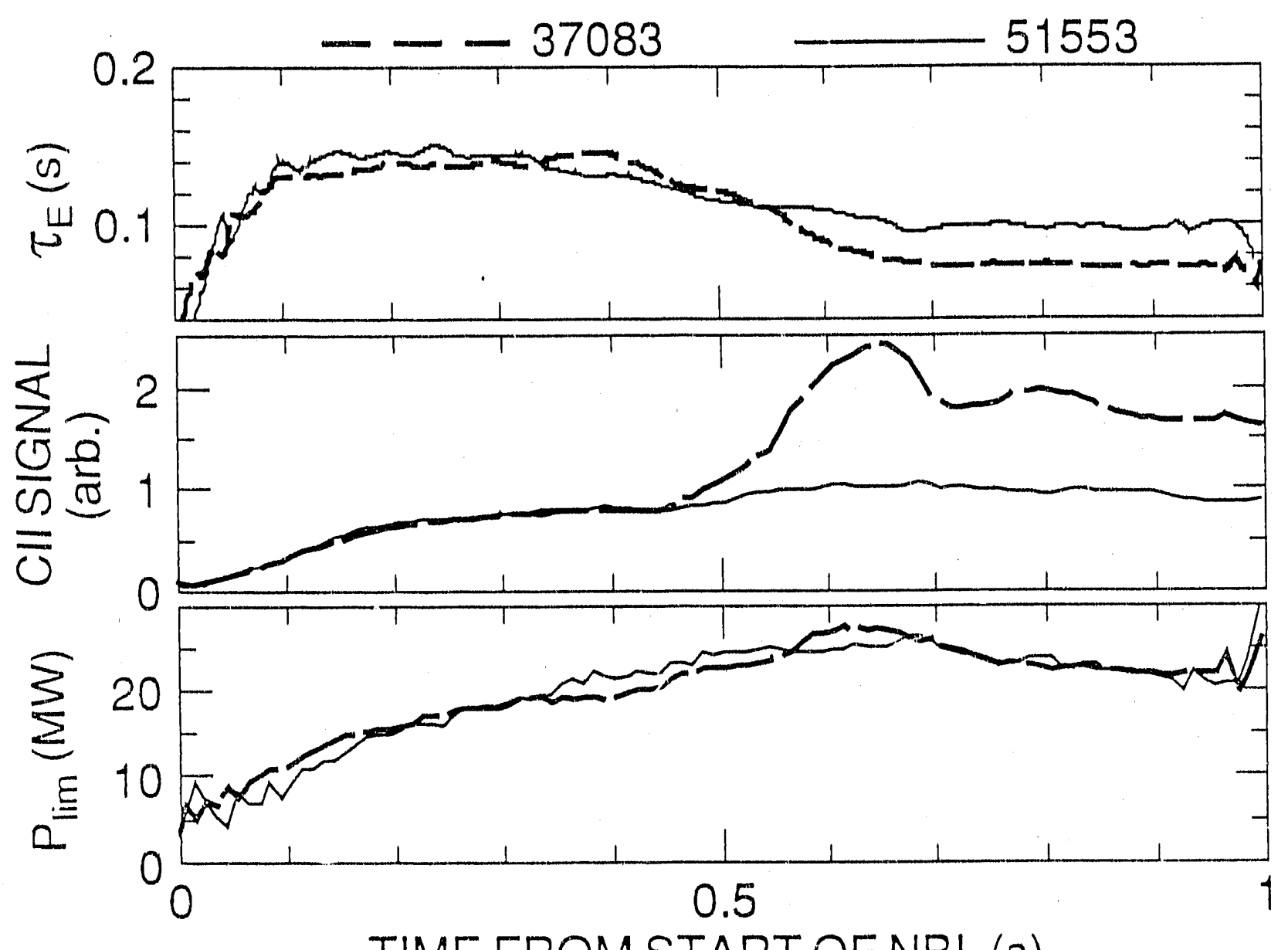

TIME FROM START OF NBI (s) 


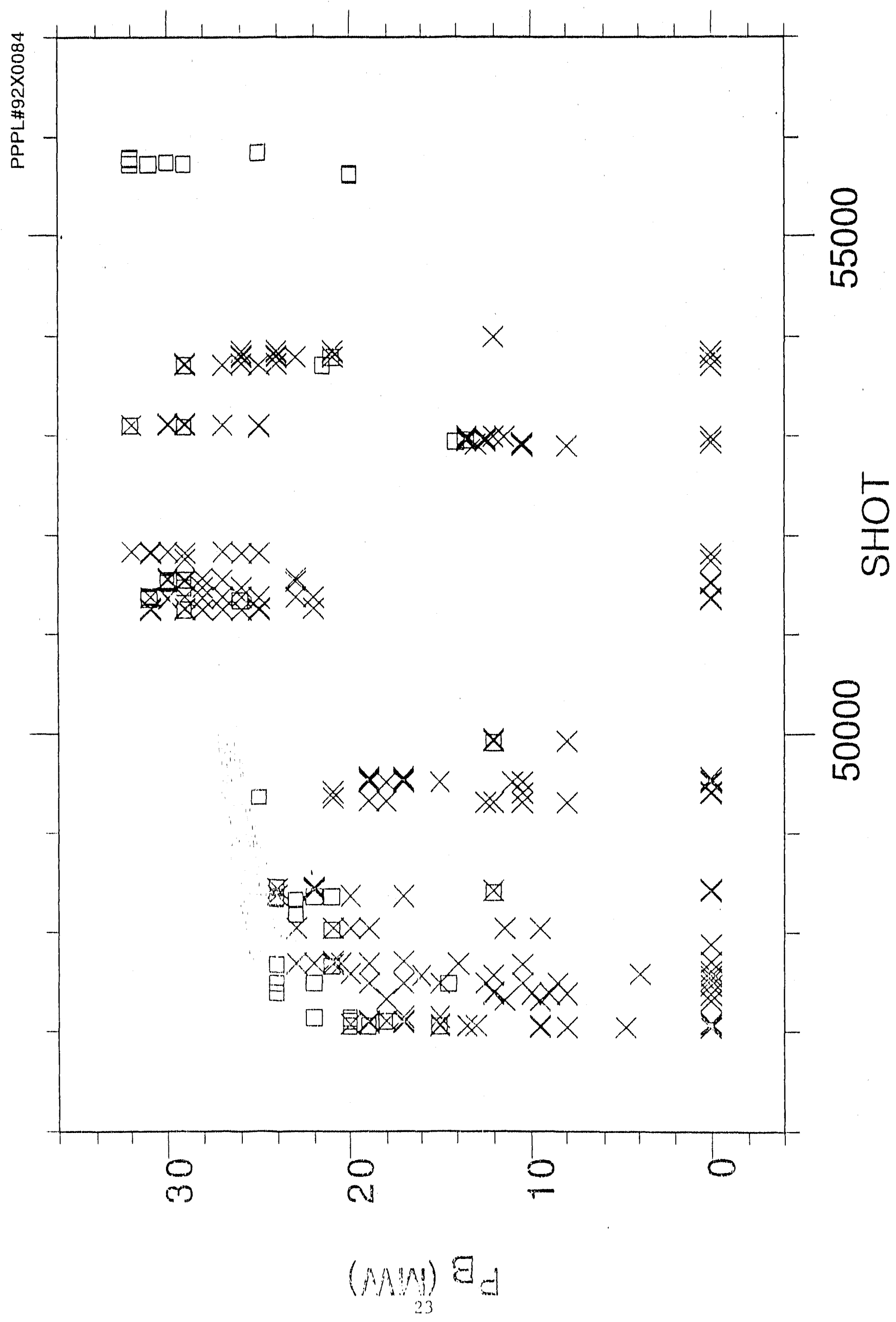




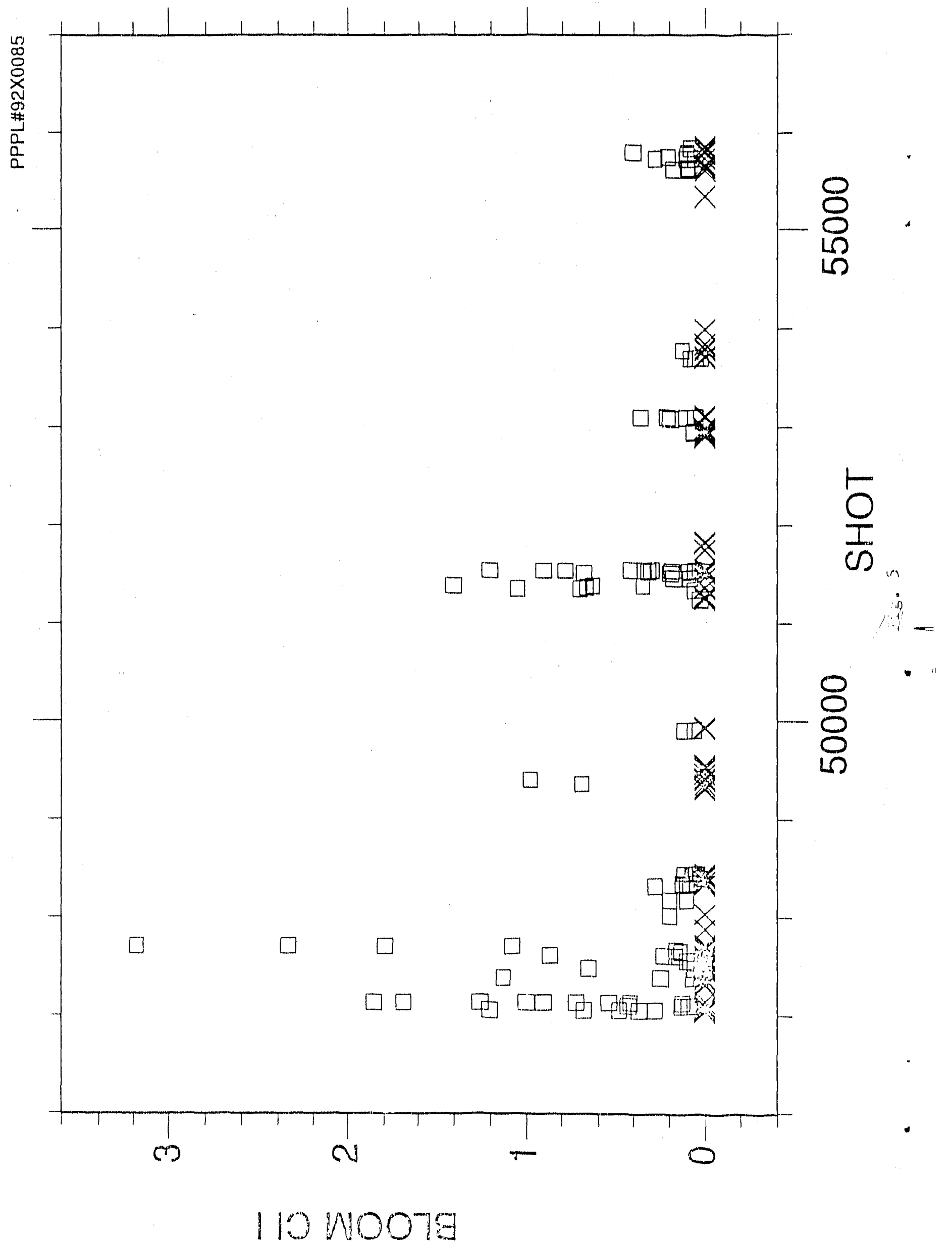




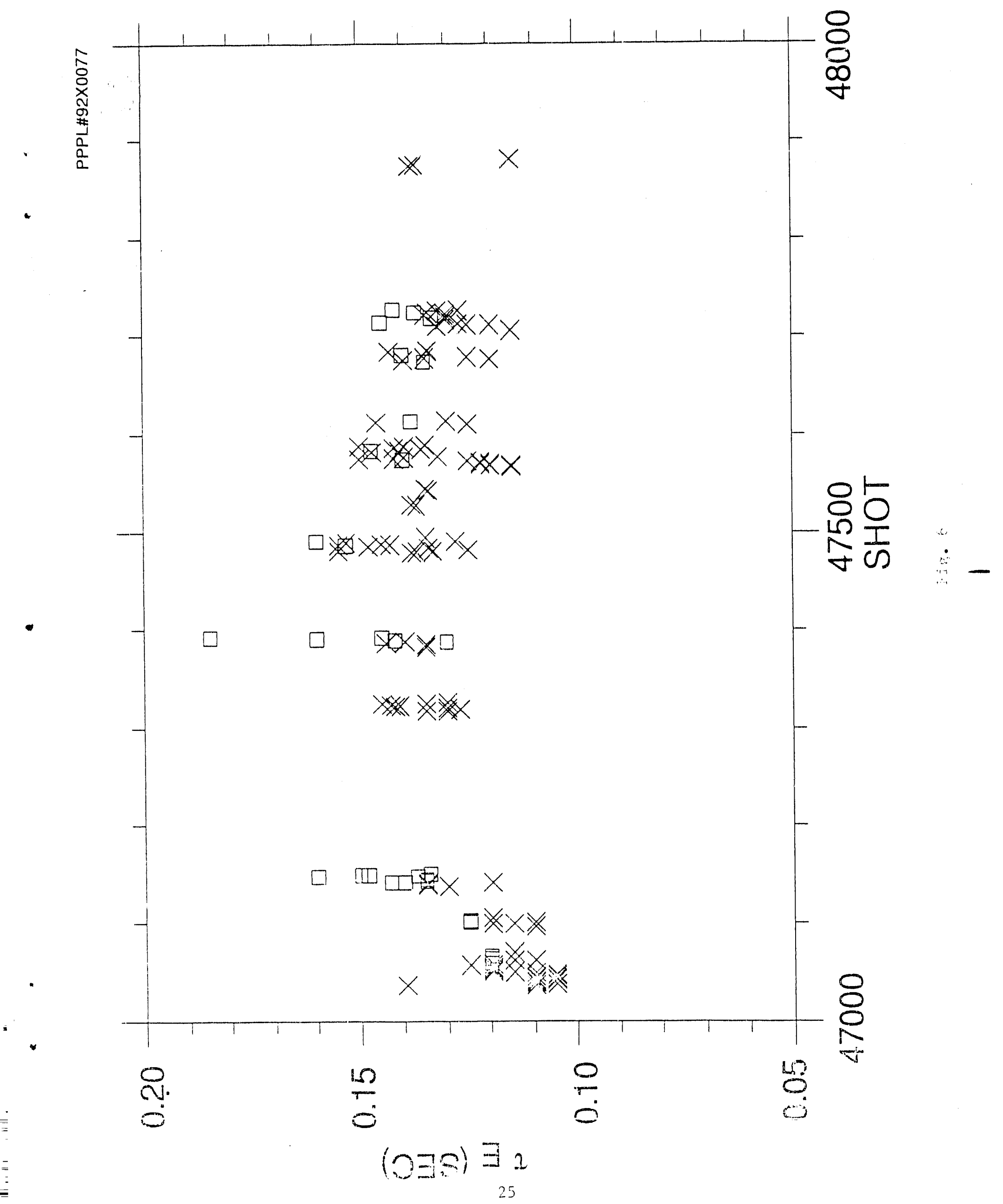




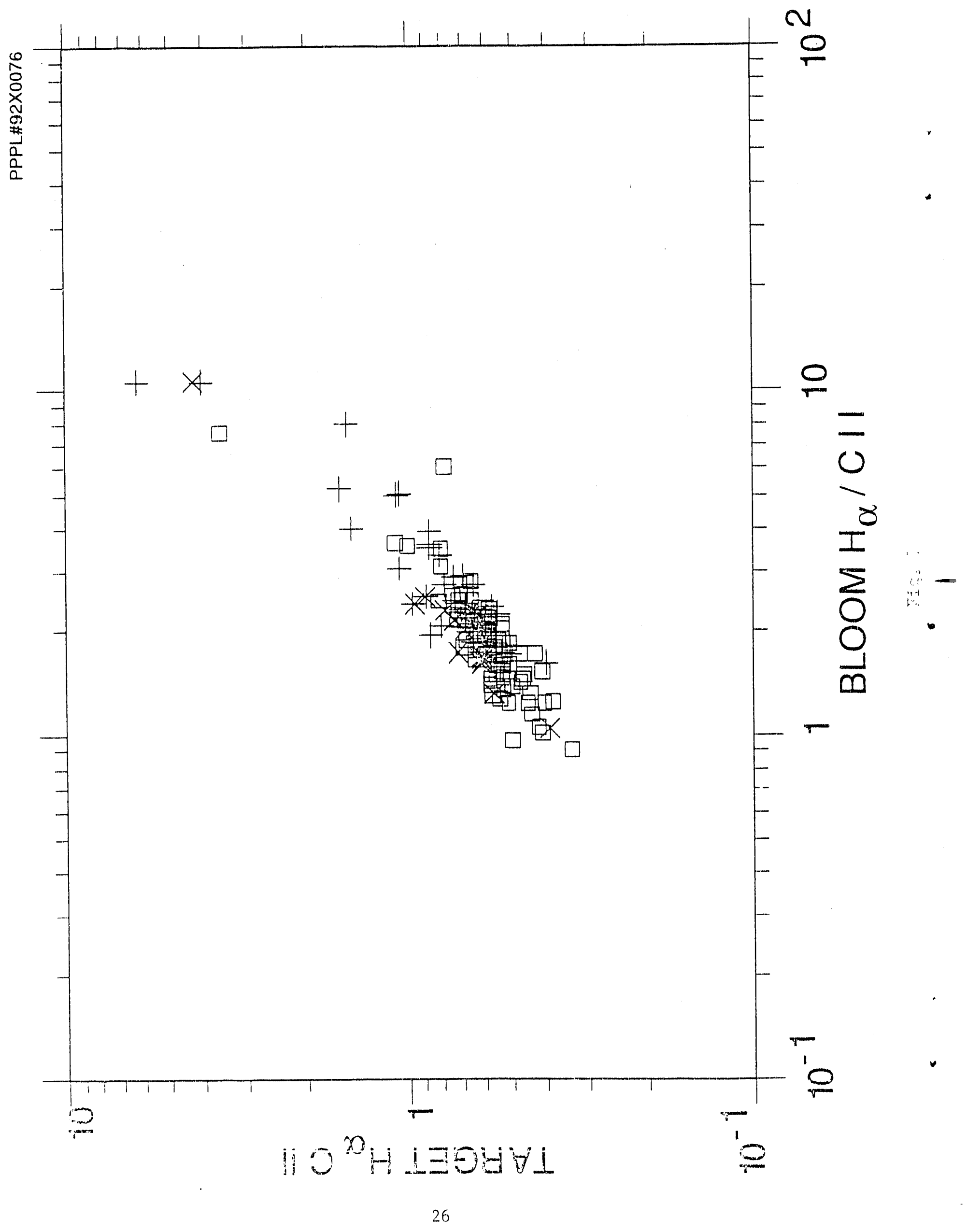




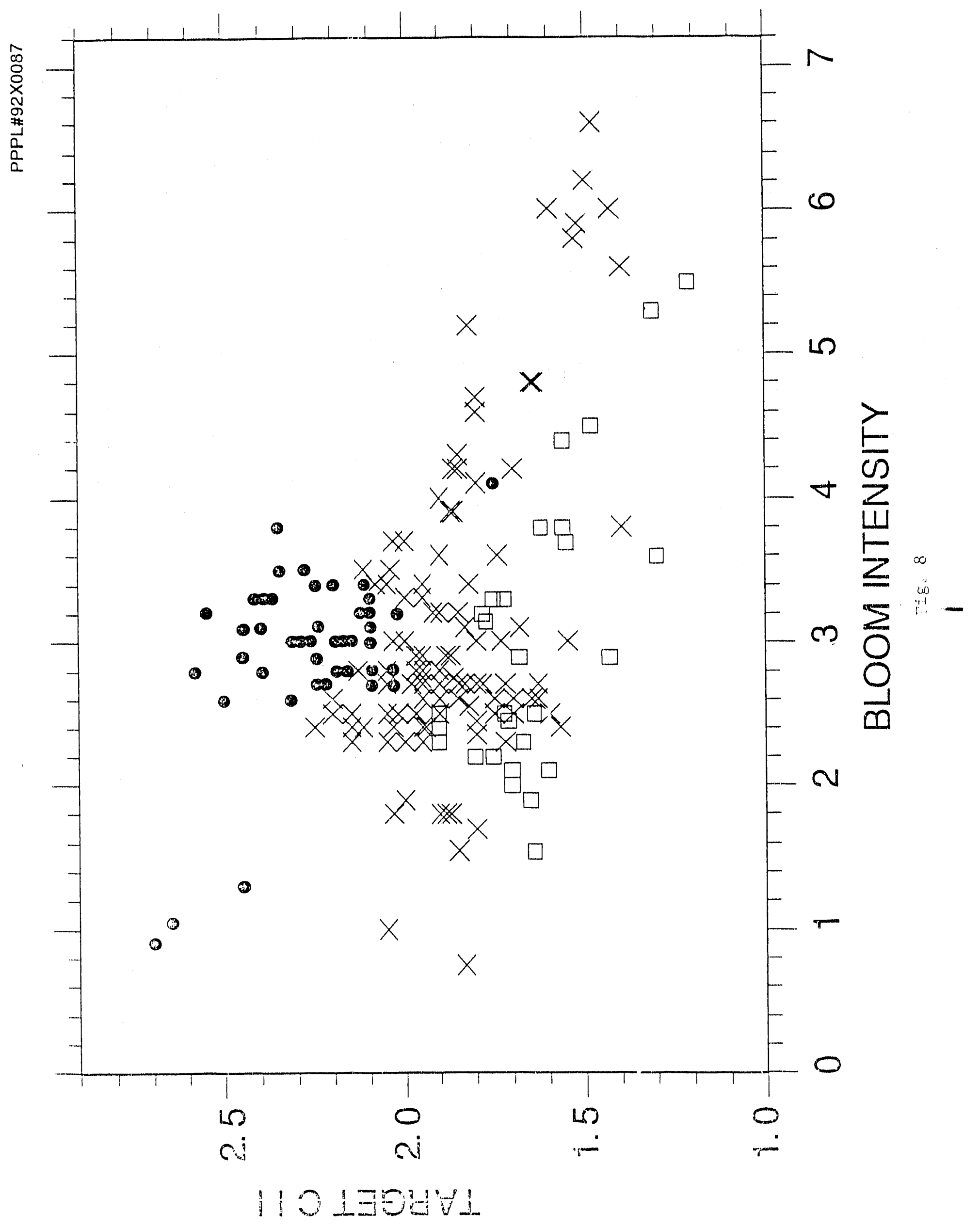




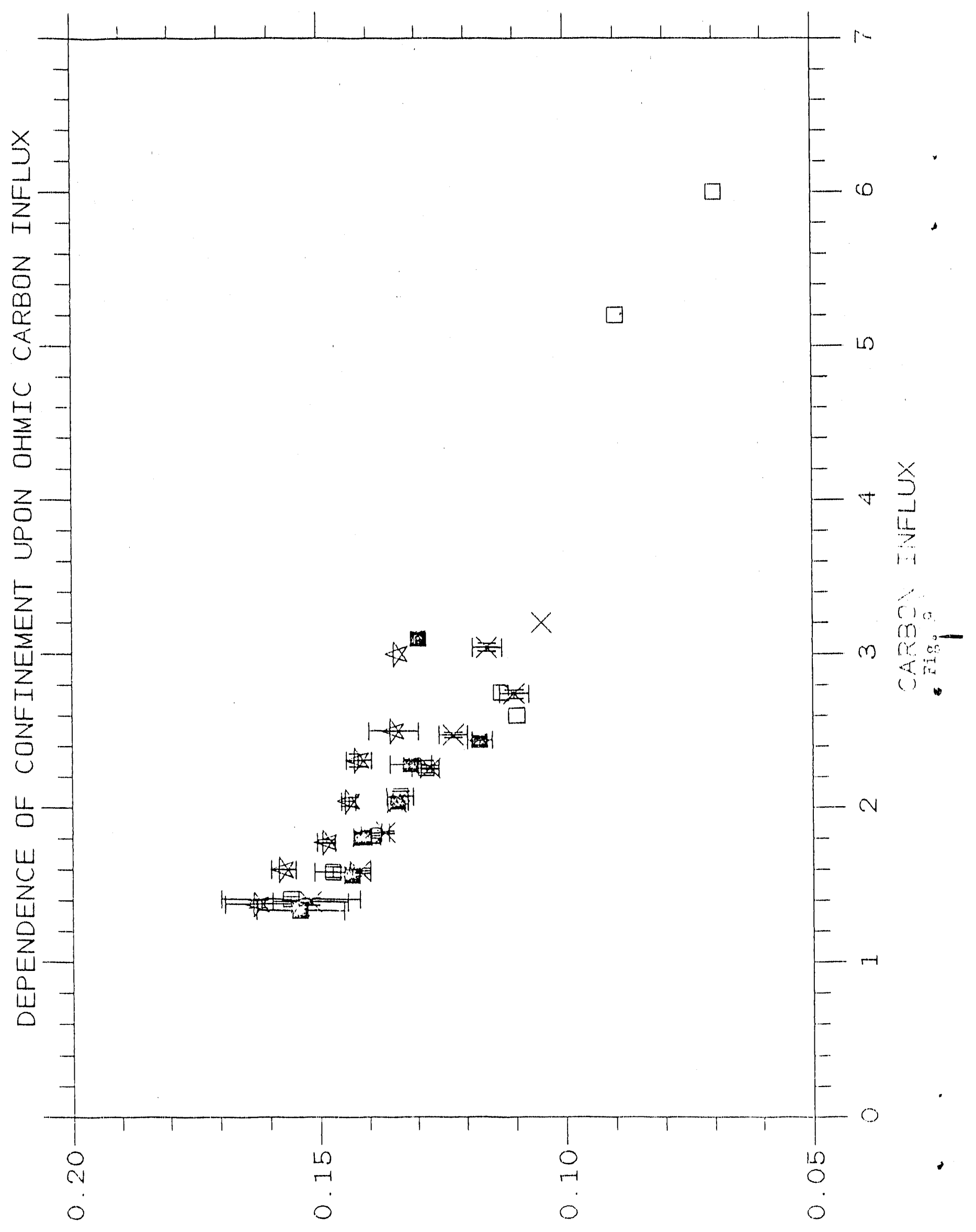

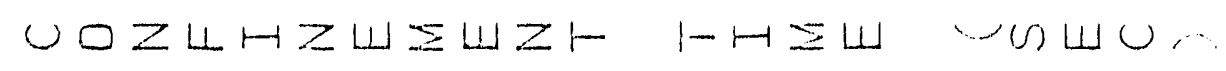




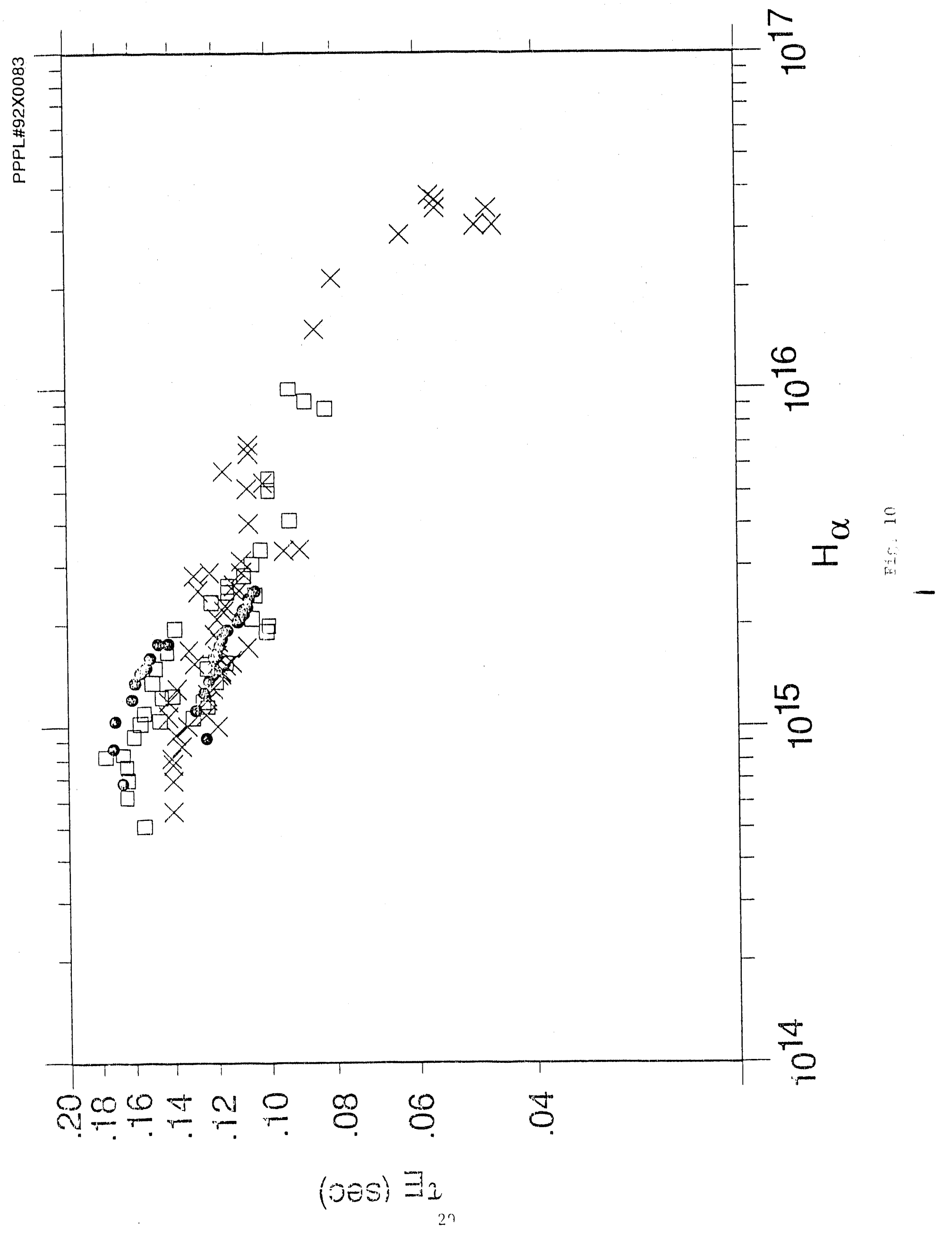




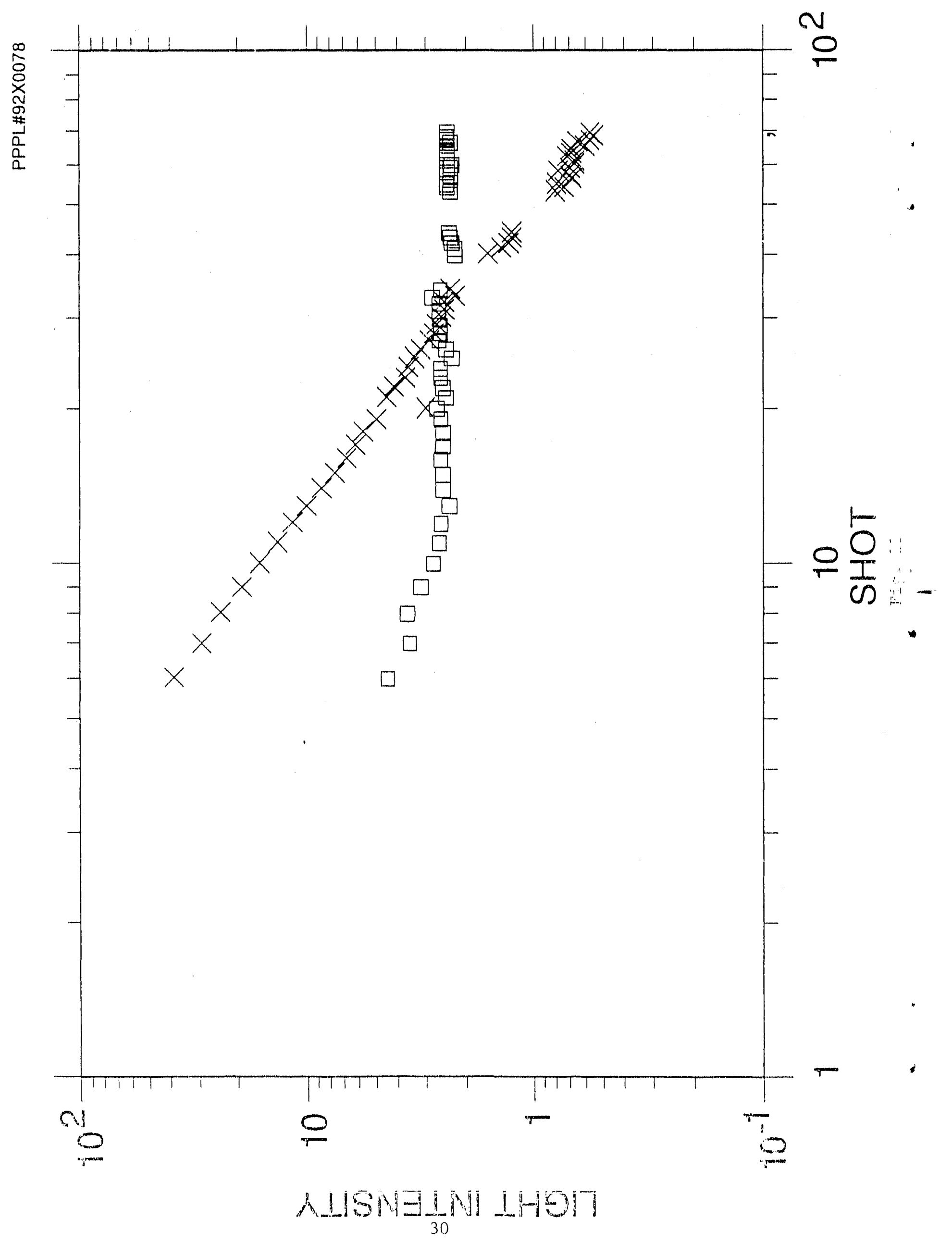




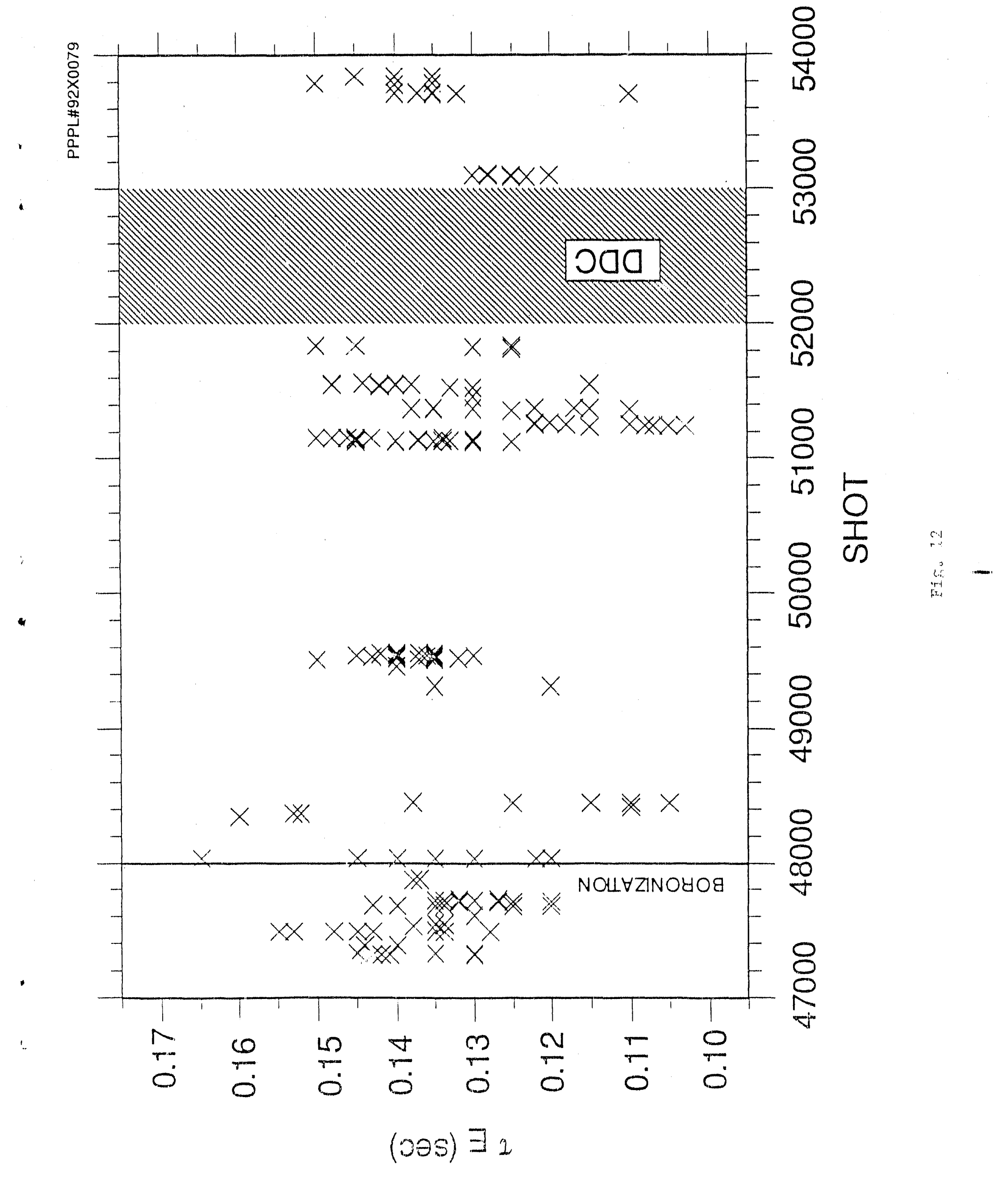


Dr. F. Peolond, Univ, of Wollongong, AUSTRALIA

Prot. M.H. Brennan, Univ. of Sydnoy, AUSTRALIA

Plasma Research Lab., Austraban Nat. Univ., AUSTRALIA

Prof. I.R. Joned, Flinders Univ, AUSTRALIA

Prof. F. Cap, Inst for Theorotical Physics, AUSTRIA

Prof. M. Heinder, Institut for Theoredseche Physik, AUSTRIA

Prof. M. Gooseons, Astronomiecth instituUt, BELGIUM

Ecole Royalo Millwire, Lab. do Pry. Plasmas, BELGIUM

Commission-European, DG. XII.Fusion Prog., BELGIUM

Prol. R. Bouciqus, Rikeunivendwit Gent, BFLGIUM

Dr. P.H. Sakanaka, Instituto Ficica, BRUZIL

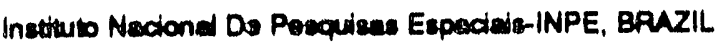

Documents Orico, Atomic Energy of Ceneda Ld., CANADA

Dr. M.P. Bechynakj, MPB Technologies, Inc., CANADA

Dr. H.M. Skarsoard, Univ. of Sackakchewen, CANADA

Prof. J. Teictimam, Univ. of Montreal, CANADA

Prot. S.R. Sreenivasem, Univ. of Caipary, CANADA

Prol. T.W. Johnston, INRS-Energio, CANADA

Dr. P. Botton, Contre canadien de tusion maynátique, CANADA

Dr. C.R. James, Univ. of Abertu, CANADA

Dr. P. Luklesc, Komencketro Universzita, CZECHO-SLOVAKIA

The Lubrarian, Cuham Loboratory, ENGLAND

Library, R61, Ruthertord Appleton Laboratory, ENGLAND

Mrs. S.A. Hulchinson, JET Libray, ENGLAND

Dr. S.C. Shame, Univ, of South Pacific, FIJI ISLANDS

P. Mahonen, Univ. of Helsinki, FINLAND

Prot. M.N. Buseac, Ecole Polytechrique, FRANCE

C. Mouter, Lab. de Physiqua dos Milioux lonises, FPANCE

J. Radel, CENCADARACHE - Bat 506, FRANCE

Prot. E. Economou, Unir. of Crete, GREECE

Ms. C. Rinni, Univ. of laarnina, GREECE

Dr. T. Mud, Acadomy Bibliographic Ser., HONG KONG

Preprint Library. Hungarian Acadomy of Sri., HUNGARY

Dr, B. DasGupta, Saha inst. of Nuctoer Physics, INDIA

Dr. P. Kaw, Inst. for Plasma Research, INDIA

Dr. P. Rosenau, Iaraed Inst. of Tochnotogy, ISPAEL

Librarian, Intermationd Center for Theo Physics, ITALY

Miss C. De Palo, Astociazione EUPATOM-ENEA, ITALY

Dr. G. Grosso, Istituto of Fiejica det Plasma. ITALY

Prof. G. Rostangni, Istituto Gas lonizzati Dol Cnr, ITALY

Dr. H. Yamato, Toshiba Ros \& Devel Centor, JAPAN
Prof. I. Kemakani, Hroshirna Univ., JAPAN

Prot. K. Nishikawa, Hiroshime Univ., JAPAN

Director, Japen Atomic Energy Research Inst., JAPAN

Prot. S. Itoh, Kyushu Univ., JAPAN

Reseanch Into, Ctr., National Instil. for Fusion Science, JAPAN

Prot. S. Tenaka, Kyoto.Univ., JAPAN

Lborary, Kyow Univ., JAPAN

Prot. N. Inowe, Univ, of Tokyo, JAPAN

Socrotany, Plasma Saction, Electrotochnical Lab., JAPAN

S. Mori, Tectmical Advicor, LAERI, LAPAN

Dr. O. Miterei, Kumamoto Inst. of Technotogy, JAPAN

J. Hywon-Sook, Korea Alomic Enorgy Reseanch Inst, KOREA

D.I. Chod, The Korea Adv. Inst. of Sal \& Tech., KOREA

Prof. B.S. Liley, Univ. of Waikato, NEW ZEALAND

In'st of Phyala, Chinese Acad Sa PEOPLE'S REP. OF CHINA

Library, Inat. of Plasma Physics, PEOPLE'S REP. OF CHINA

Tainghua Univ. Library, PEOPLE'S REPUBLIC OF CHINA

2. Li, S.W. In Physics, PEOPLE'S REPUBLIC OF CHINA

Prol. J.A.C. Cebrad, Instiuto Superior TEcrico, PORTUGAL

Dr. O. Porus, ALI CUZA Univ., ROMANIA

Dr. J. do Villers, Fusion Studies, AEC, S. AFRICA

Prot. M.A. Hellberg, Unir. of Naral, S. AFRICA

Prot. D.E. Kim, Pohang Inst. of Sal. \& Tech, SO. KOREA

Prof. C.I.E.M.A.T. Fusion Division Lubrary, SPAIN

Dr. L Stonfio, Univ. of UMEA, SWEDEN

Library, Royed inst. of Tectinology, SWEDEN

Prot. H. Withaimson, Chaimer Univ. of Tech., SWEDEN

Contro Phys. Des Plasmas, Ecolo Polytech, SWITZERLAND

Biblotheok, Inst. Voor Plasma-Fysica, THE NETHERLANDS

Asst. Prot. Dr. S. Cakir, Midde East Toch. Univ., TURKEY

Dr. V.A. Gluktikh,Sai. Res. Inst. Electrophys.I Apparatus, USSR

Dr. D.D. Ayutov, Siberian Branch of Acadomy of Sa., USSA

Dr. G.A. Elleoev, I.V. Kurchatov Inst, USSA

Librarion, The Ukr.SSA Academy of Sciences, USSA

Dr. LM. Kovizhmykh, Inst. of General Physics, USSA

Kemtorectungsantege GmbH, Zentralbibliothek, W. GERMANY

Bibliothok, Inst. For Plasmalorechung, W. GERMANY

Prot. K. Sctinder, Ruhr-Universitat Bochum, W. GERMANY

Dr. F. Wogner, (ASDEX), Max-Planck-Institut, W. GERMANY

Litorarian, Max-Plenck-Inetiturt, W. GERMANY

Prot. R.K. Janev, Inst of Ptysics, YUGOSLAVIA 

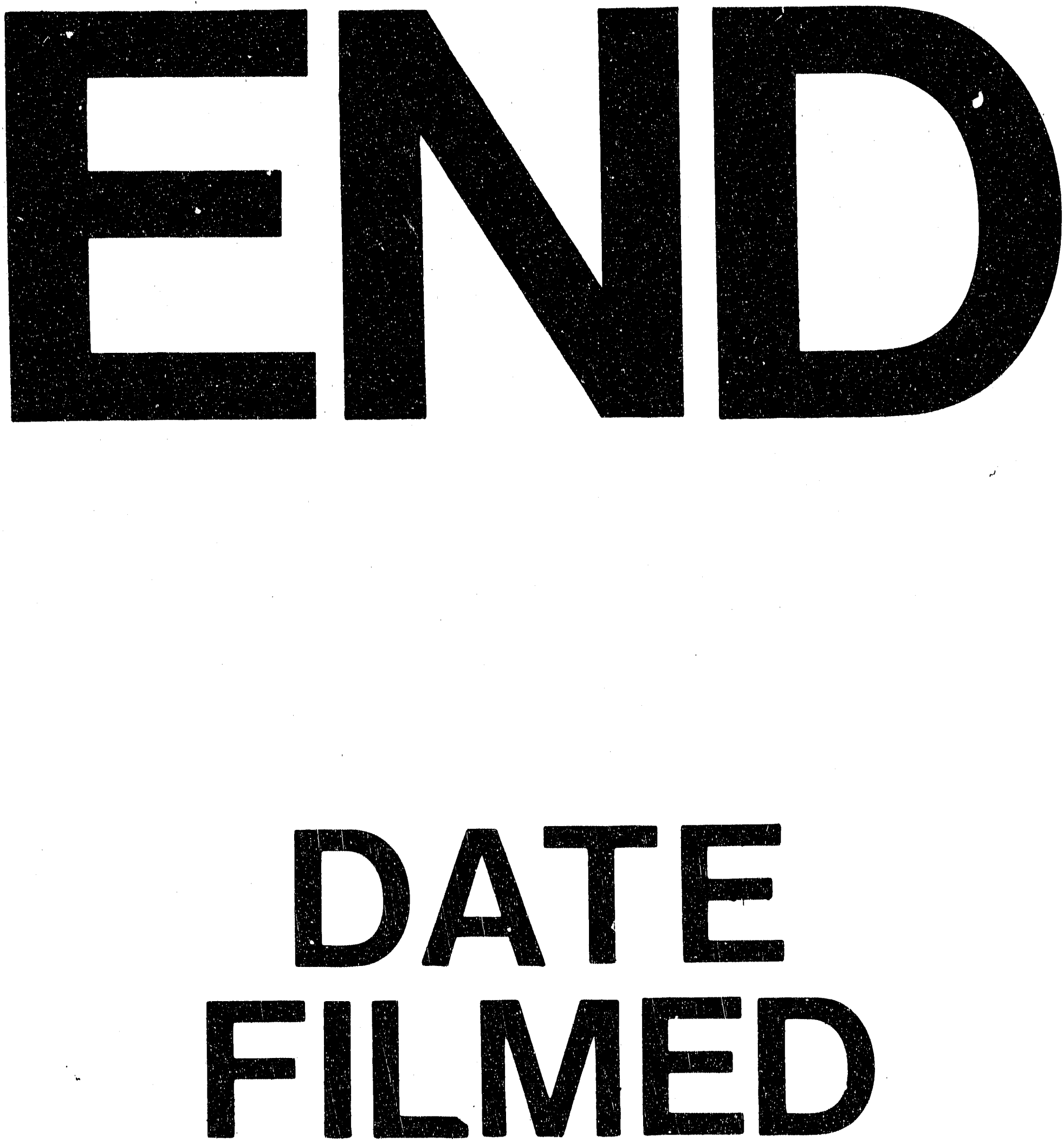

I

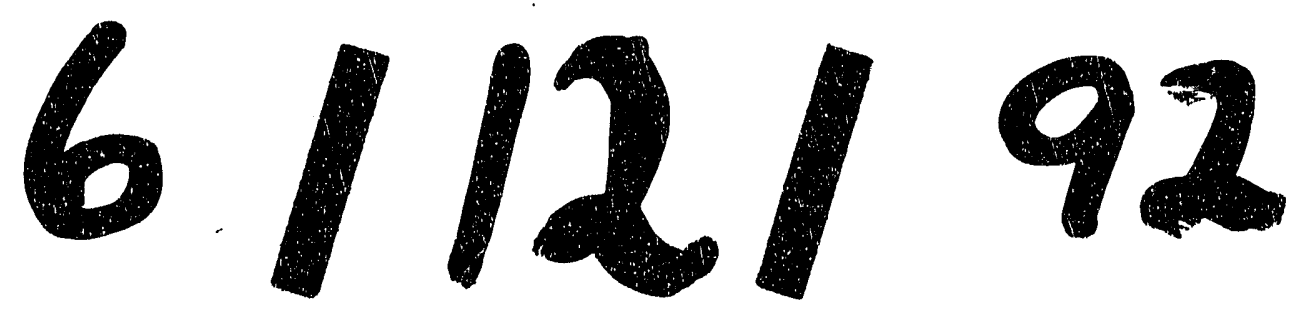


